\title{
The Effect of Speed Factors and Horn Sound to The RLS 90 Model Reliability on The Visum Program in Predicting Noise of Heterogeneous Traffic
}

\author{
Muralia Hustim ${ }^{1}$, Muhammad Isran Ramli ${ }^{2}$, Rasdiana Zakaria ${ }^{1}$, Zulfiani AR $^{2}$ \\ ${ }^{1}$ Department of Environmental Engineering, Hasanuddin University, INDONESIA. \\ ${ }^{2}$ Department of Civil Engineering, Hasanuddin University, INDONESIA.
}

Received 01 January 2018; accepted 15 April 2018, available online 07 May 2018

\begin{abstract}
This study aimed to predict the noise generated by heterogeneous traffic using RLS 90 model on the Visum program, evaluating and looking for correction factor. Points of observation were taken at 37 points on the road side at $06.00-18.00$ and $06.00-21.00$ with research object are motorcycle, light vehicle and heavy vehicle. The observed data are traffic volume, vehicle speed, number of horn and traffic noise by using Sound Level Meter Tenmars TM-103. The result shows the prediction model of RLS 90 Visum program produces an average noise level value of $69.3 \mathrm{~dB}$ with Pearson's correlation and RMSE of 0.71 and 9.97, the prediction model RLS 90 vehicle correction produces an average noise level value of $77.9 \mathrm{~dB}$ with Pearson's correlation and RMSE of 0.75 and 2.02, whereas the prediction model RLS 90 vehicle and horn correction produces an average noise level value of $79.1 \mathrm{~dB}$ with Pearson's correlation and RMSE of 0.83 and 1.29. So that, prediction model RLS 90 with vehicle and horn correction quite good which has a relationship of $\mathrm{Y}=0.71 \mathrm{X}+29.65$ to the prediction model RLS 90 with Visum program.
\end{abstract}

Keywords: RLS 90 Model, Visum Program, road traffic noise, vehicle, horn

\section{Introduction}

The problem of traffic noise is one of the factors that affect environmental safety in both developed and developing countries. Research in Tehran, Iran as a developing country shows that traffic noise level affects health especially in psychology (Alimohammad et al., 2015). Previous research showed average noise level of roadside of Makassar City reached $74 \mathrm{~dB}$ (Hustim et al., 2011). Vehicle speed is one of the factors affecting the traffic noise level where the average speed of vehicles in Makassar City reaches less than $40 \mathrm{~km} / \mathrm{h}$ (Hustim et al., $2012 b$ ). Besides the vehicle speed, another factor that affects the noise level is the number of horns. Hustim and Fujimoto (2012a), are looking for horn power level through vehicle testing that considerate the distance from the horn to SLM. Then proceed with measurement of noise level in 35 streets in Makassar City and make the prediction model.

The RLS 90 model (Richtlinien fur den Larmschutz an Straben) is one of the prediction models that originally from Germany. The Visum program is the world's leading software for modeling the macroscopic transportation needs of traffic networks, with the addition of functions that can also analyze the external effects of traffic such as air pollution and noise levels. The noise calculation on the Visum program uses the prediction model RLS 90. Novačko et al (2014), conducted a research to illustrate the methodology of noise level evaluation by implementing the Visum software at the European Project Civitas ELAN in the city of Zabreg.

The prediction model RLS 90 used in the Visum program has been set by the system so that users can only input the correction data provided in the program. So it is necessary to evaluate the prediction results by using the basic formula of the prediction model in the Excel program so that in the end can be detected correction factors that affect the prediction results.

\section{Numerical Model}

The value of $L_{A e q}$ and $L_{A e q, \text { day }}$ (daily equivalent) obtained through the calculation using equation 1 and equation 2.

With,

$$
L_{\text {Aeq }}=L_{50}+0.43\left(L_{1}+L_{50}\right)
$$

$L_{\text {Aeq }}=$ Equivalent Noise Level $(\mathrm{dB})$,

$L_{50}=50 \%$ Noise Level (dB),

$L_{1}=99 \%$ Noise Level (dB). 


$$
L_{\text {Aeq, day }}=10 \log 10\left[\left(\frac{1}{t n}\right) \cdot\left(10^{\frac{L_{e q} 1}{10}}\right)+\cdots+\left(10^{\frac{L_{e q} t n}{10}}\right)\right]
$$

With;

$$
\begin{array}{ll}
L_{\text {Aeq,day }} & =\text { Daily Equivalent Noise Level }(\mathrm{dB}) \\
L_{e q} t n & =\text { Daily Noise Level } \mathrm{n}(\mathrm{dB}) \\
t n & =\text { Number of measurement in a day }
\end{array}
$$

The basic formula of noise level measurement RLS 90 prediction based on Quartieri et.al (2009) in equation 3.

$L_{m}=L_{M, E(25)}+R_{S L}+R_{R S}+R_{R F}+R_{E}+R_{D A}+R_{G A}+R_{T B}$

With:

$R_{S L}=$ Correction for Speed Limit

$R_{R S}=$ Correction for road surface, based on type of surface and speed vehicle. Scale from 0 to $6 \mathrm{~dB}$.

$R_{R S}=0.6 \operatorname{lgl}-3$ for $|g|>5 \%$

$R_{R S}=0$ for $|g| \leq 5 \%$

$R_{R F}=$ Correction for up and down condition in entire road (height)

$R_{E}=$ Correction for the absorption characteristics of the building surface

$R_{D A}=$ The damping coefficients are incorporated into the calculation of the distance from the receiver and the absorption of air

$R_{G A}=$ The coefficient of damping that occurs in soil and air conditions

$R_{T B}=$ The coefficient of damping that occurs on the topography and dimensions of the building.

To calculate $R_{S L}$ used equation 4 and Equation 5

With,

$$
R_{S L}=L_{P k w}-37.3+10 \log \left(\frac{100+\left(10^{0.1 D}-1\right) P}{100+8.23 P}\right)
$$

$$
\begin{aligned}
L_{P k w} & =27.7+10 \log \left[1+\left(0.02 v_{P k w}\right)^{3}\right] \\
L_{L k w} & =23.1+12.5 \log \left(v_{P k w}\right) \\
D & =L_{L k w}-L_{P k w}
\end{aligned}
$$

Where $v_{P k w}$ is speed limit on scale 30 until $130 \mathrm{~km} / \mathrm{h}$ for light vehicle and $v_{L k W}$ is speed limit on scale 30 until $80 \mathrm{~km} / \mathrm{h}$ for heavy vehicle.

Evaluation of $L_{m, E^{[25]}}$ for each segment can be seen in equation 6

$$
L_{m}=10 \log \left[10^{0.1 L_{m, n}}+10^{0.1 L_{m, f}}\right]
$$

Where $\mathrm{n}$ represents the closer and $\mathrm{f}$ for the respective path respectively.

The calculation of the noise level of a vehicle honk that refers to Asakura research (2010) is calculated using equation 7 and equation 8 .

$$
L_{A h}=10 \log 10\left(\sum 10^{\frac{L_{A}}{10}}\right) \Delta t\left(41 \times 3.6 \times\left(\frac{d}{V}\right)\right)
$$

Where: 


\section{Result and Discussion}

\subsection{Result of Measurement}

\section{Noise Level}

The value of noise level resulted from the measurements can be seen in figure 2 where $L_{\text {Aeq, day }}$ maximum value was obtained on Jalan Urip Sumoharjo 2 with amount of $82.4 \mathrm{~dB}$. While the minimum value of $L_{A e q, \text { day }}$ was obtained on Jalan Urip Sumoharjo with amount of $74.4 \mathrm{~dB}$. The average $L_{\text {Aeq, day }}$ of each point measurements was $79.1 \mathrm{~dB}$.

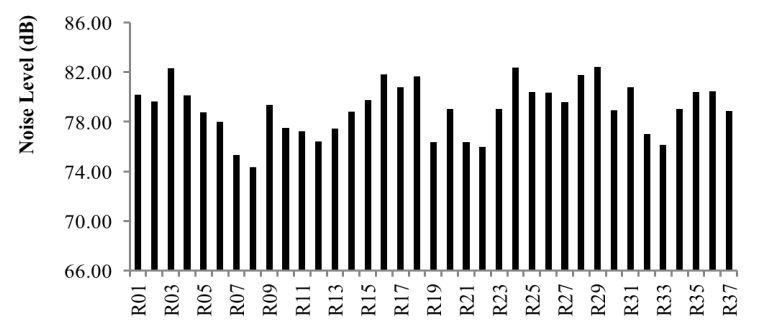

Measurement Point

Fig. 2 Noise level from measurement

\section{Number of Vehicle}

As shown in figure 3 , the highest vehicle volume is obtained from motorcycles and the lowest vehicle volume is obtained from heavy vehicle. Observation point on road with the highest traffic volume is Jalan Perintis Kemerdekaan 2. Whereas the lowest traffic volume is Jalan Haji Bau. The average traffic volume for motorcycles is 4571 vehicles / hour, light vehicles of 1795 vehicles / hour, and heavy vehicles of 86 vehicles / hour.

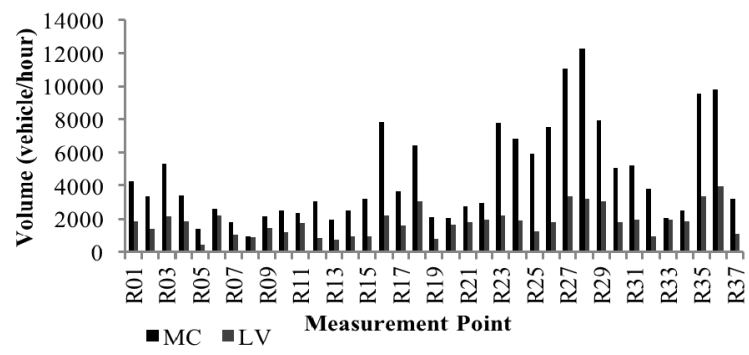

(a) Motorcycles and light vehicles traffic volume

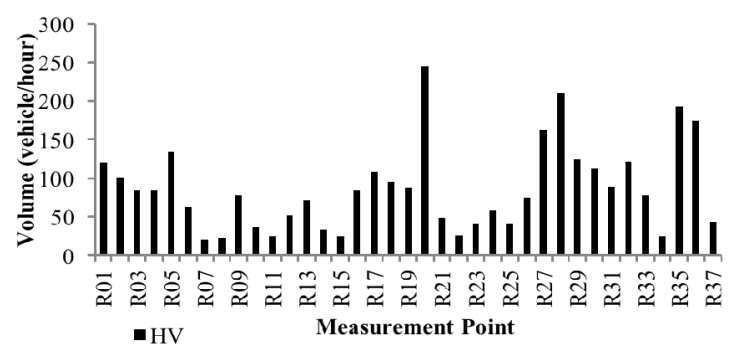

(b) Heavy vehicles traffic volume

Fig. 3 Number of Vehicle

\section{Speed of Vehicle}

Figure 4 shows that the average speed of a motorcycle is $30 \mathrm{~km} / \mathrm{h}$, light vehicles of $26 \mathrm{~km} / \mathrm{h}$ and heavy vehicles of $24 \mathrm{~km} / \mathrm{h}$. Observation point on Jalan Sultan Alauddin 1 has the highest average speed of 32 $\mathrm{km} / \mathrm{h}$ while the observation point on Jalan Masjid Raya has the lowest average speed of $21 \mathrm{~km} / \mathrm{h}$.

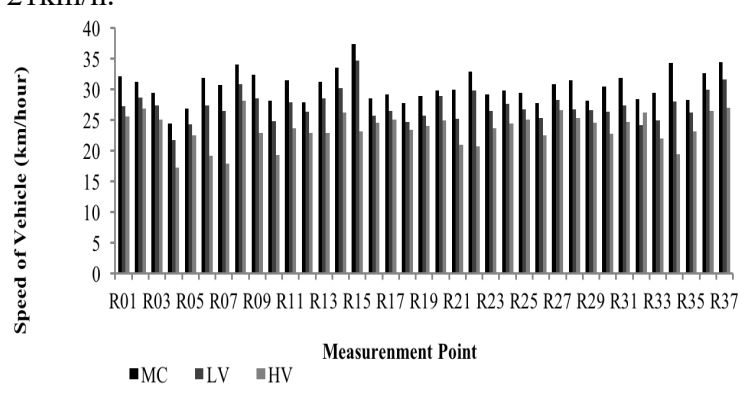

Fig. 4 Speed of Vehicle

\section{Number of Horn Vehicle}

The calculation of the number of horns in figure 5 shows the value of horn sounds issued by motorcycles as much as 122 - 738 times / hour, light vehicles $90-662$ times / hour, and heavy vehicles as much as 1- 89 times / hour. The highest number of horns of 1433 times / h was obtained at the point of observation with the AP Road segment. Pettarani 1, while the observation point with the lowest horn noise amounted to 227 times / h was obtained on the Perintis Kemerdekaan 3 Road segment.

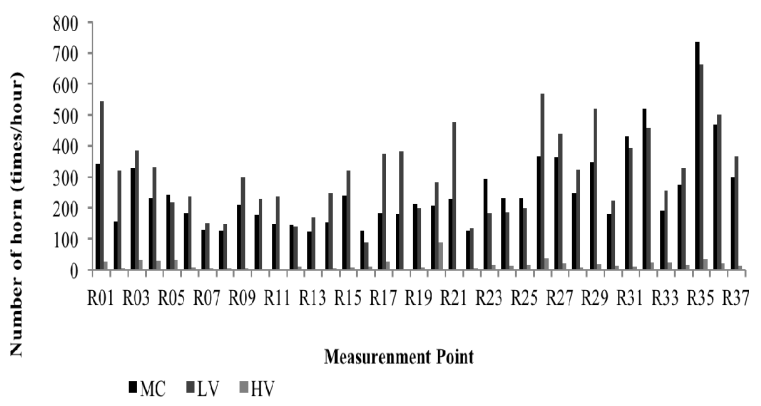

Fig. 5 Number of Horn Vehicle

The traffic volume on each type of road is different so as to produce different noise levels. In addition to traffic volume, vehicle speed also affects the noise level. The speed of a vehicle is affected by the capacity and volume of the road. Roads that have large capacity but low volume, then the vehicle speed can be increased so that noise is also increased. However, if the volume is high, the vehicle speed will decrease, but does not guarantee the noise will decrease due to high traffic volume. As in the Jalan Veteran Selatan segment which is a large road type $(6 / 2 \mathrm{D})$, but due to the high volume 
during peak hours the noise increases even though the speed decreases.

Another variable that also affects the traffic noise level is the number of horns issued from vehicles that cross the measurement point. The measurement point with a high percentage of the horn will produce a high level of noise. AP Pettarani 1 road segment with 8/2D road type and high volume, produces high amount of horn so it also has high noise level.

\subsection{Noise Level Predicted Results RLS 90 with Visum Program}

The RLS 90 prediction model operated with the Visum program requires variables such as road characteristic data, length of road and lane width, total traffic volume, heavy vehicle percentage, free traffic flow velocity and road capacity. The traffic volume used is the total traffic volume of the three types of vehicles; light vehicles, heavy vehicles and motorcycles. The speed of free flow of traffic and road capacity is calculated based on Road Capacity Manual of Indonesia (MKJI). The comparison of noise level of measurement result and noise level of RLS 90 with Visum program can be seen in Figure 6.

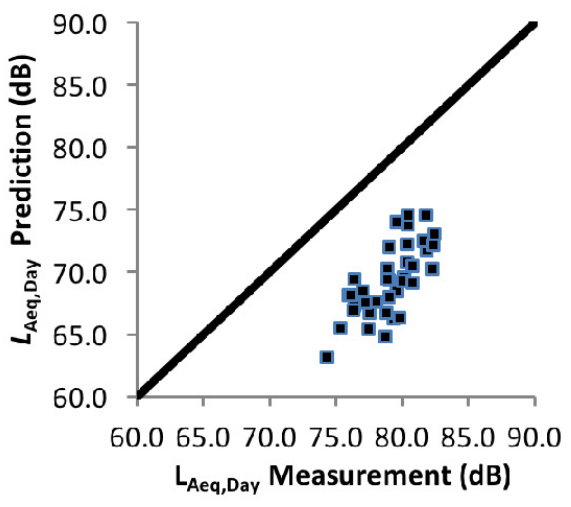

Fig. 6 Noise Level Prediction

The average $L_{\text {Aeq, day }}$ value for all measurement points is $69.3 \mathrm{~dB}$. Based on Figure 6, there is a considerable difference between the measured noise noise level and the predicted noise level. The resulting average difference is $9.8 \mathrm{~dB}$ below the measured noise level. Validation of data is done to the predicted noise level value so that the correlation value of pearson 0.71 and RMSE 9.97 is obtained. The validation results obtained show that this model is not valid enough to be used to predict the noise level.

\section{Noise Level of RLS 90 Predicted Result with Speed Correction}

Evaluation of RLS 90 model prediction results is done by speed correction using the basic formula of the model with data in the total volume of vehicles, the percentage of vehicle weight and vehicle speed. The comparison of the noise level of the measurement and the noise level of the predicted RLS 90 with the speed correction can be seen in Figure 7.

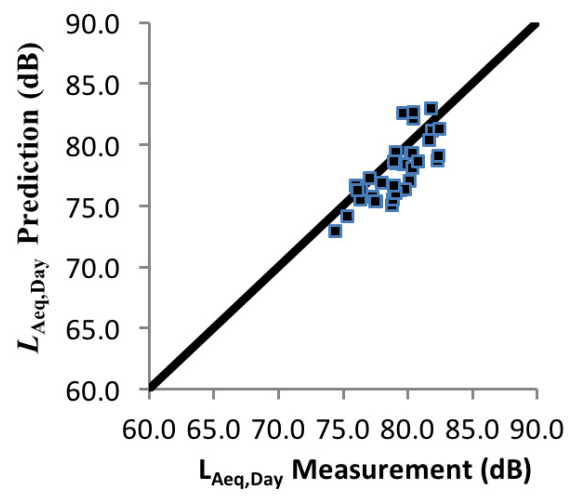

Fig. 7 Noise Level Prediction with Speed Correction

The average $L_{\text {Aeq, day }}$ value for all measurement points is $77.9 \mathrm{~dB}$. Based on Figure 7, the predicted noise level results is close to the measurement noise level. Validation of data is done on the predicted noise level value so that the correlation value of pearson 0.75 and RMSE 2.02 is produced. Validation results obtained show that this model is valid enough to predict the noise level, but still needed correction to be closer to measurement result.

\section{Noise Level of RLS 90 Predicted Results with Speed Correction and Horn Sound}

After evaluation with speed correction, then the evaluation is done with speed correction plus the correction of honking. The data required for speed correction is the same as the previous data, while for the correction of honking it is required the data on the number of horns that can be seen in Figure 5. Then it is calculated on the basis of equation 7 and summing the result with the predicted speed of the predicted speed correction based on equation 8 . The comparison of the noise level of the measurement and the noise level of the predicted RLS 90 with the speed and horn correction can be seen in Figure 8. 


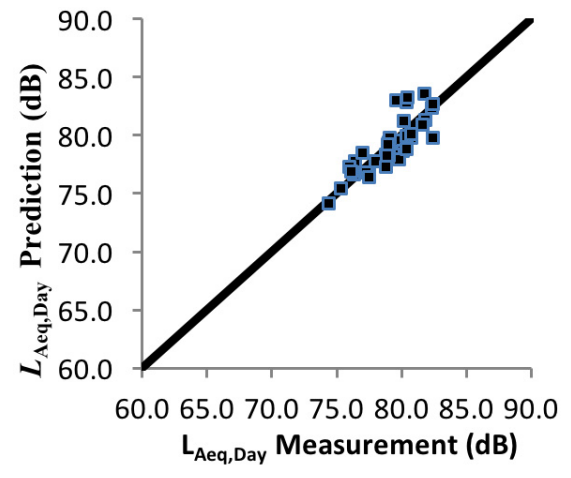

Fig. 8 Noise Level Prediction with Speed \& Horn Correction

The average $L_{\text {Aeq, day }}$ value for all measurement points is $79.1 \mathrm{~dB}$. Based on Figure 8, the predicted noise level results are very close to the measurement noise level. Validation of data is done on the predicted noise level value so that the correlation value of pearson 0.83 and RMSE 1.29 are obtained. Validation results obtained show that this model is valid enough to be used to predict the noise level.

In Figure 9 we can see the linear regression relationship between the prediction model RLS 90 speed correction and the horn with prediction model RLS 90 Visum program. The resulting equation model is $\mathrm{Y}=$ $0.71 X+29.65$.

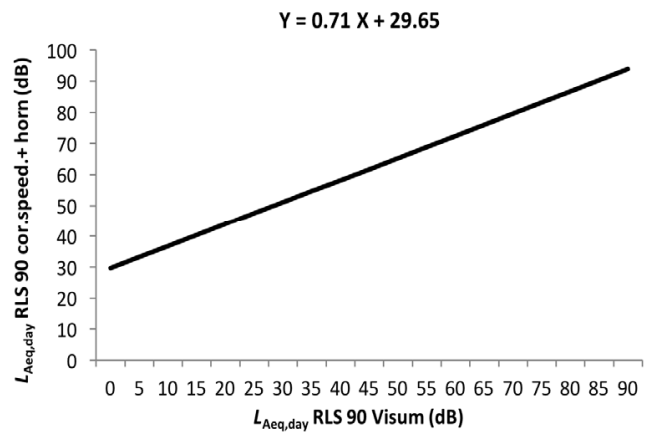

Fig. 9 Graph of regression model of RLS prediction model 90 speed correction and horn sound with prediction model RLS 90 Visum program

Based on the analysis, the predicted noise level obtained based on the RLS 90 model with the Visum program and the RLS 90 model with speed correction and the horn sound has a significant difference of $9.8 \mathrm{~dB}$. This is because the use of the Visum program is a macroscopic transportation analysis program. The program processes the data in outline, so there are some variables that should be taken into account to predict the noise level, but not used as input data in the Visum program as there is a valid range for very high speed so it is not suitable for heterogeneous conditions in Makassar. In addition, the data on the number of horns is also not taken into account in the Visum program, while the horn sound also includes one of the influential sounds in the traffic noise level.

Unlike the noise level of predicted RLS 90 results with speed correction and honking are calculated in the Excel program. The basic formula of the RLS 90 prediction model can be easily used in the Excel program by using the average speed of the vehicle and the horn data at the time of measurement so that the predicted results obtained are also closer to the measured noise level. Therefore, it can be seen that the correction factor that influences in the calculation so that the differences in predictions model RLS 90 with the program Visum and manual calculations in the Excel program is the speed of the vehicle and the horn.

\section{Summary}

The noise level of the predicted RLS 90 results using the Visum program of $69.3 \mathrm{~dB}$ with the correlation value of pearson 0.71 and RMSE 9.97.

Evaluation done by using Excel program resulted predictive noise level value of $79.1 \mathrm{~dB}$ with correlation value of pearson 0.83 and RMSE 1.29, where the resulting difference is $9.8 \mathrm{~dB}$.

The correction factor obtained is the vehicle speed and the horn sound according to the measurement results that need to be included in the calculation.

\section{References}

[1] Alimohammad, I., Zokaei, M., dan Sandrock, S. 2015. The Effect of Road Traffic Noise on Reaction Time. Health Promotion Perspectives, (Online), 5(3), 207-214, (http://doi.org/10.15171/hpp.2015.025, 12 Mei 2016).

[2] Asakura, T., Sakamoto, S., Rahman, M. 2010. Noise Measurement in Dhaka City, Proceedings of the 2010 Autumn Meeting of INCE/J. pp.15-18.

[3] Hustim, M., Anai, K. dan Fujimoto, K. 2011. Survey on Road Traffic Noise in Makassar City Indonesia. Inter Noise. Kyushu University, Japan.

[4] Hustim, M., and Fujimoto, K. 2012a. Acoustical Characteristics of Horn Sound of Vehicle. Journal of Architecture and Urban Design, Kyushu University, Japan.

[5] Hustim, M. 2012b. Road Traffic Noise under Heterogeneous Traffic Condition in Makassar City. Journal of Habitat Engineering and Design. 4(1), 109-118.

[6] Novačko, L., Petrović, M., dan Barić, D. 2014. Application of Macroscopic Modelling in Assessing. International Journal for Traffic and Transport Engineering. 4(1), 117-127.

[7] Quartieri, J., Mastorakis, N., Iannone, G., Guarnaccia, C., D’Ambrosio, S., Troisi, A., dan Lenza, T. 2009. A Review of Traffic Noise Predictive Models. Recent Advances in Applied and Theoretical Mechanics, (december), 72-80. 